\title{
GAMBARAN PEMANFAATAN KMS OLEH KADER POSYANDU BALITA SEHAT DI DUSUN BEDOYO KIDUL,DESA BEDOYO, KECAMATAN PONJONG, KABUPATEN GUNUNGKIDUL, YOGYAKARTA
}

\author{
Intan Nugroho ${ }^{1}$, Budi Rahayu ${ }^{1}$ \\ ${ }^{1}$ Stikes Jen. A.Yani Yogyakarta \\ JI. Ringroad Barat, Ambarketawang, Gamping, Sleman, D.I.Yogyakarta
}

\begin{abstract}
Background:A sensitive indicator to monitor child growth is weight changes. Monitoring children health is one of Posyandu's (Integrated Services Post) activities. KMS is a card that is utilized to record children growth. It is very pivotal for cadres to have knowledge and skill to fill the card, especially the weight graph, so the interpretation will be accurate. In instance, malnutrition should be early detected to provide immediate intervention.

Objective: This study aimed to explore the KMS utilizationby cadres at Posyandu "Balita Sehat" in Bedoyo Kidul, Bedoyo village, Ponjong Sudistrict, Gunungkidul Regency.

Research method: This was a survey study, with non-analytic descriptive design. Population was 12 active cadres in Bedoyo Kidul, Bedoyo village, Ponjong Sudistrict, Gunungkidul Regency. All cadres were involved in this study.

Research result: The result showed that the KMS utilization by cadres was in poor category, both for knowledge and follow-up intervention (9 respondents, $75 \%$ ).

Conclusion: The KMS utilization by cadres in Bedoyo Kidul, Bedoyo village, Ponjong Sudistrict, Gunungkidul Regency was in poor category.
\end{abstract}

Key words: KMS utilization, Cadres

\section{PENDAHULUAN}

KMS adalah kartu yang memuat kurva pertumbuhan normal anak berdasarkan indeks antropometri berat menurut umur, dengan KMS gangguan pertumbuhan atau risiko kelebihan gizi dapat diketahui lebih dini, sehingga dapat dilakukan tindakan pencegahan secara lebih cepat dan tepat sebelum masalahnya lebih berat. KMS di Indonesia telah digunakan sejak tahun 1970an sebagai sarana utama kegiatan pemantauan pertumbuhan. ${ }^{(1)}$.

Estimasi jumlah balita di Indonesia tahun 2013 mencapai 23.708.844 jiwa dan jumlah balita yang ditimbang sebanyak 10.891.462 jiwa. Hal tersebut menunjukkan perkiraan selisih 12.817.382 jiwa ${ }^{(2)}$.
Menurut hasil Riskesdas tahun 2013 terjadi peningkatan persentase balita dengan gizi buruk dan gizi kurang menurut Berat Badan per Umur (BB/U) di Indonesia sebesar 1,7\%. Tahun 2013 mencapai 19,6\%, sedangkan pada tahun 2010 mencapai persentase sebesar 17,9\%. Berdasarkan laporan hasil pemantauan status gizi tahun 2012, peta balita di Bawah Garis Merah per Umur $(B G M / U)$ di Daerah Istimewa Yogyakarta (DIY) belum mencapai target khususnya di kabupaten Gunung Kidul yaitu sebesar $2 \%$ dari target yang diharapkan di DIY yaitu sebesar 1\%. Peningkatan balita dengan gizi buruk dan gizi kurang kemungkinan terjadi karena adanya balita yang tidak terdeteksi atau tersembunyi dan 
juga karena kesalahan pencatatan tumbuh kembang bayi dan balita pada buku Kartu Menuju Sehat (KMS) dilakukan oleh kader.

Pada saat ini pemantauan pertumbuhan merupakan kegiatan utama posyandu. Jumlah posyandu hingga tahun 2013, yang tersebar di 33 provinsi di Indonesia sekitar 330.000. Sedangkan capaian posyandu aktif di DIY pada tahun 2012 sebesar 75,52\%, jika dilihat dari strata perkembangannya, Posyandu Pratama sebesar 4\%, Posyandu Madya sebesar 21\%, Posyandu Purnama sebesar 47\%, dan Posyandu Mandiri sebesar $28 \%{ }^{(2)}$. Masih rendahnya cakupan posyandu mandiri perlu mendapatkan perhatian, terutama untuk penggerakan peran serta masyarakat dan promosi kesehatan yang lebih intensif dengan memanfaatkan berbagai media promosi. Posyandu digerakkan oleh para kader secara sukarela yang peduli dengan perkembangan kesehatan dan gizi anak Indonesia. Pelaksanaan programprogram posyandu memerlukan kerja sama dari berbagai pihak terkait di antaranya perangkat desa, kader kesehatan, pemuda, Lembaga Swadaya Masyarakat (LSM), dan seluruh warga masyarakat pada umumnya.

Kader bertugas untuk melakukan penimbangan berat badan bayi, menentukan status pertumbuhan berdasarkan kurva KMS serta memberikan penyuluhan dan konseling gizi. $^{(3)}$

Berdasarkan Survei Kesehatan Rumah Tangga (SKRT) tahun 2005 hanya $46,6 \%$ kader posyandu yang pernah mendapat pelatihan tentang KMS. Menurut $58,6 \%$ kader yang disurvei, penggunaan KMS adalah untuk memantau pertumbuhan balita. Persentase kader aktif nasional adalah $69,2 \%$ dan kader drop out sebesar $30,8 \%{ }^{(4)}$. Banyak terjadinya angka putus (drop out) ataupun pergantian kader tanpa diikuti pelatihan atau retraining menyebabkan lemahnya pengetahuan kader dalam memberikan pelayanan, salah satunya pengetahuan tentang KMS. Hal ini akan mengakibatkan kegiatan pemantauan pertumbuhan balita yang dinilai dari KMS tidak dapat dilakukan secara optimal, sehingga upaya pemantauan menjadi kurang efektif. Akibatnya pemanfaatan KMS sebagai sarana penyuluhan gizi dinilai masih rendah. Ini membuktikan bahwa masih lemahnya pengetahuan kader tentang KMS bila ditinjau dari aspek pemanfaatan KMS.

Rumusan masalah dalam penelitian ini yaitu bagaimana pemanfaatan KMS oleh Kader Posyandu Balita Sehat di dusun Bedoyo Kidul, Desa Bedoyo, Kecamatan Ponjong, Kabupaten Gunung Kidul. Penelitian ini bertujuan untuk mengetahui gambaran pengetahuan kader posyandu tentang KMS dan pemanfaatan KMS oleh Kader Posyandu Balita Sehat di dusun Bedoyo Kidul, Desa Bedoyo, Kecamatan Ponjong, Kabupaten Gunung Kidul.

\section{BAHAN DAN CARA PENELITIAN}

Penelitian ini menggunakan metode penelitian survei observasional, rancangan 
diskriptif non analitik dengan pendekatan kuantitatif. ${ }^{(5)}$

Penelitian dilakukan di Desa Bedoyo, Kecamatan Ponjong, Kabupaten Gunung Kidul pada bulan Juni 2015 dengan teknik total sampling untuk pengambilan sampel dan pengisian kuesioner serta lembar observasional untuk pengambilan data. Menurut Sugiyono (2007), total sampling adalah penentuan sampel atau semua anggota populasi digunakan sebagai sampel (6).

Sampel dalam penelitian ini adalah seluruh kader yang berjumlah 12 kader yang aktif di Desa Bedoyo, Kecamatan Ponjong, Kabupaten Gunung Kidul.

Data dianalisis secara univariat yang dilakukan terhadap tiap variabel hasil penelitian.

\section{HASIL DAN PEMBAHASAN}

Hasil penelitian menunjukkan bahwa karakteristik responden kader Posyandu Balita Sehat dusun Bedoyo Kidul, Bedoyo, Ponjong Gunung Kidul seperti yang terlihat pada tabel 1.

Tabel 1 Distribusi Karakteristik

Kader Posyandu Balita Sehat

\begin{tabular}{llcc}
\hline No & Karakteristik Responden & $\mathrm{f}$ & $\%$ \\
\hline 1 & Umur & & \\
& $20-35$ tahun & 8 & 66.7 \\
& $36-45$ tahun & 4 & 33.3 \\
\hline Total & 12 & $100 \%$ \\
\hline 2 & Lama menjadi kader & & \\
& 1-3 tahun & 7 & 58.3 \\
\multicolumn{2}{l}{$>$ > tahun-6 tahun } & 5 & 41.7 \\
\hline Total & Pendidikan & 12 & $100 \%$ \\
\hline 3 & SMP & 2 & 16.7
\end{tabular}

\begin{tabular}{llcc}
\hline No & Karakteristik Responden & $f$ & $\%$ \\
\hline \multicolumn{2}{l}{ SMA } & 9 & 75.0 \\
\multicolumn{1}{l}{ Perguruan Tinggi } & 1 & 8.3 \\
\hline Total & & 12 & $100 \%$ \\
\hline 4 & Pelatihan mengenai KMS & & \\
& Pernah & 9 & 75.0 \\
\multicolumn{1}{l}{ Betal } & 3 & 25.0 \\
\hline Belum & 12 & $100 \%$ \\
\hline
\end{tabular}

(Sumber : data primer 2015)

Berdasarkan tabel 1 karakteristik responden menunjukkkan bahwa umur responden paling banyak antara 20-35 tahun dengan jumlah 8 kader $(66.7 \%)$, lama responden menjadi kader paling banyak yaitu 1-3 tahun dengan jumlah 7 kader (58.3\%), pendidikan responden paling banyak pada tingkat SMA yaitu 9 kader (75.0\%), dan sebanyak 9 responden (75.0\%) pernah mengikuti pelatihan mengenai KMS.

Tabel 2 Distribusi Frekuensi Tingkat Pemanfaatan KMS

\begin{tabular}{cccc}
\hline No & Kategori & $\mathbf{f}$ & $\%$ \\
\hline 1 & Baik & 0 & 0 \\
2 & Cukup & 3 & 25.0 \\
3 & Kurang & 9 & 75.0 \\
\hline & Total & 12 & $100 \%$ \\
\hline
\end{tabular}

(Sumber : data primer 2015)

Tabel 2 menunjukkan bahwa sebagian besar responden memiliki tingkat pemanfaatan KMS pada kategori kurang sebanyak 9 responden (75.0\%).

Masih kurangnya pemanfaatan KMS oleh kader posyandu disebabkan karena kurangnya keberanian dan pengetahuan yang dimiliki oleh kader posyandu terutama kemampuan kader posyandu dalam mengisi grafik berat badan secara benar dan menafsirkan kurang.

Sehingga akan berakibat terjadinya penafsiran pertumbuhan dan tidak diketahui penyimpangan. Hal ini seperti diungkapkan 
oleh Lenocoly dalam bukunya tahun 2008, bahwa gizi buruk yang seharusnya terdeteksi secara dini tak dapat dilakukan pada akhirnya terjadilah keterlambatan dalam intervensi dan penatalaksaannya. Apabila kader mampu mengisi grafik berat badan dan menafsirkan KMS dengan benar maka keadaan kurang gizi akan cepat terdeteksi dan tertangani sehingga status gizi balita diharapkan menjadi baik ${ }^{(6)}$.

Hasil penelitian tersebut tidak sesuai dengan teori dari manfaat KMS bagi kader menurut Permenkes RI nomor 155/Menkes/Per///2010 yaitu KMS digunakan untuk mencatat berat badan anak, mencatat pemberian kapsul vitamin $A$, menillai hasil penimbangan, dan memberikan pujian kepada ibu bila berat badan anaknya naik, serta mengingatkan ibu untuk menimbangkan anaknya di posyandu pada bulan berikutnya. Pada kenyataan di lapangan banyak kader yang kurang memanfaatkan KMS dan hanya memegang KMS tanpa menjelaskan isi dari KMS sesuai kebutuhan bayi atau balita tersebut ${ }^{(8)}$.

Tabel 3 Distribusi Frekuensi Tingkat Pemanfaatan KMS Mengenai Pengetahuan tentang KMS

\begin{tabular}{cccc}
\hline No & Kategori & $\mathbf{f}$ & $\%$ \\
\hline 1 & Baik & 0 & 0 \\
2 & Cukup & 3 & 25.0 \\
3 & Kurang & 9 & 75.0 \\
\hline & Total & 12 & $100 \%$ \\
\hline
\end{tabular}

(Sumber : data primer 2015)

Tabel 3 menunjukkan bahwa sebagian besar responden kader posyandu memiliki pengetahuan kader mengenai pemanfaatan
KMS pada kategori kurang sebanyak 9 responden $(75.0 \%)$.

Hasil penelitian di atas menggambarkan bahwa sebagian besar kader posyandu di dusun Bedoyo Kidul, Bedoyo, Ponjong, Gunung Kidul hanya mampu menimbang dan mengisi pada buku penimbangan. Hal ini tidak sejalan dengan Permenkes (2011) bahwa kader bertugas untuk melakukan penimbangan berat badan bayi, menentukan status pertumbuhan berdasarkan kurva KMS, serta memberikan penyuluhan dan konseling gizi $^{(3)}$.

Hasil penelitian tersebut juga tidak sejalan dengan teori yang ada dalam Peraturan Menteri Kesehatan RI (2010) yang menyebutkan bahwa tujuan KMS sebagai alat memantau pertumbuhan anak ${ }^{(8)}$. Pada KMS dicantumkan grafik pertumbuhan normal anak, yang dapat digunakan untuk menentukan apakah seorang anak tumbuh normal, atau mengalami gangguan pertumbuhan. Bila grafik berat badan anak mengikuti grafik pertumbuhan pada KMS, artinya anak tumbuh normal kecil risiko anak untuk mengalami gangguan pertumbuhan. Sebaliknya bila grafik berat badan tidak sesuai dengan grafik pertumbuhan, anak kemungkinan berisiko mengalami gangguan pertumbuhan.

Pada praktiknya, pengetahuan kader yang dinilai dari jawaban kuesioner menunjukkan bahwa sebagian besar kader kurang paham dengan KMS tersebut. Sebagai kader kesehatan khususnya kader 
Posyandu balita seharusnya dapat mengerti komponen dalam KMS dan penggunaannya. Sehingga penyimpangan-penyimpangan seperti kesalahan penafsiran berat badan dapat segera diatasi.

Tabel 4 Distribusi Frekuensi

Tingkat Pemanfaatan KMS

Mengenai Penggunaan KMS

\begin{tabular}{cccc}
\hline No & Kategori & f & $\%$ \\
\hline 1 & Baik & 0 & 0 \\
2 & Cukup & 4 & 33.3 \\
3 & Kurang & 8 & 66.7 \\
\hline & Total & 12 & $100 \%$ \\
\hline
\end{tabular}

(Sumber : data primer 2015)

Tabel 4 menunjukkan bahwa sebagian besar kader posyandu memiliki pemanfaatan KMS oleh kader posyandu di dusun Bedoyo Kidul, Bedoyo, Ponjong, Gunung Kidul mengenai penggunaan KMS pada kategori kurang sebanyak 8 responden (66.7\%).

Kurangnya pemanfaatan KMS kader posyandu dalam penggunaan KMS dimungkinkan karena sulitnya pengkaderan yang dilakukan dari warga setempat untuk mengelola posyandu secara sukarela sehingga mengakibatkan pemantauan yang tidak optimal terhadap pertumbuhan balita. Hal ini seperti diungkapkan oleh Sulistyorini dkk (2010) bahwa persentase kader aktif nasional adalah $69,2 \%$ dan kader drop out sebesar $30,8 \%{ }^{(9)}$. Banyak terjadinya angka putus (drop out) ataupun pergantian kader tanpa diikuti pelatihan atau retraining menyebabkan lemahnya pengetahuan kader dalam memberikan pelayanan, salah satunya pengetahuan tentang KMS.
Dalam penelitian yang dilihat saat Posyandu, kader banyak yang tidak memberikan penyuluhan tentang gizi Hal ini akan membuat kegiatan pemantauan pertumbuhan balita yang dinilai dari KMS tidak dapat dilakukan secara optimal, sehingga upaya pemantauan menjadi kurang efektif. Akibatnya pemanfaatan KMS sebagai sarana penyuluhan gizi dinilai masih rendah. Ini membuktikan bahwa masih lemahnya pengetahuan kader tentang KMS bila ditinjau dari aspek pemanfaatan KMS.

Tabel 5 Distribusi Frekuensi

Tingkat Pemanfaatan KMS Mengenai Tindak Lanjut Penilaian KMS

\begin{tabular}{cccc}
\hline No & Kategori & $\mathbf{f}$ & $\%$ \\
\hline 1 & Baik & 0 & 0 \\
2 & Cukup & 3 & 25.0 \\
3 & Kurang & 9 & 75.0 \\
\hline & Total & 12 & $100 \%$ \\
\hline
\end{tabular}

(Sumber : data primer 2015)

Tabel 5 menunjukkan bahwa sebagian besar kader posyandu tidak dapat melakukan tindak lanjut hasil penilaian pertumbuhan balita sebanyak 9 responden (75.0\%).

Hasil penelitian ini tidak sesuai dengan Permenkes No.155 (2010) yang mengemukakan bahwa setiap kader seharusnya dapat menindaklanjuti hasil penilaian pertumbuhan balita sedangkan hasil penelitian menunjukkan bahwa responden yang dapat menindaklanjuti hasil penelitian sebanyak 3 responden ( $25 \%$ ).

Tindak lanjut yang dilakukan oleh kader Posyandu dalam praktiknya banyak kader yang tidak melakukan point-point yang tertera dalam Permenkes nomor 155 tahun 2010. Hal tersebut dapat mengakibatkan 
terlambatnya penanggulangan terhadap bayi atau balita yang mengalami masalah dalam pertumbuhannya. Apabila bayi atau balita yang seharusnya segera dirujuk ke Puskesmas atau pelayanan kesehatan yang lain tidak segera dilakukan maka akan berdampak pada status pertumbuhan khususnya untuk bayi atau balita tersebut dan juga akan berdampak pada status gizi di wilayah tersebut. Pada klasifikasi tindak lanjut apabila berat badan anak tidak naik satu kali seharusnya kader memberikan penjelasan mengenai masalah yang dialami tanpa menyalahkan ibu atau pendamping anak. Namun dalam praktiknya banyak kader yang tidak memberikan penjelasan bahkan hanya menyayangkan keadaan yang dialami anak. Sehingga ibu ataupun pendamping anak merasa bingung dan tidak mendapatkan solusi atas masalah tersebut.

\section{KESIMPULAN}

Tingkat pemanfaatan KMS oleh kader posyandu di dusun Bedoyo Kidul, Bedoyo, Ponjong, Gunung Kidul adalah kategori baik 0 responden $(0 \%)$, cukup sebanyak 3 responden $(25.0 \%)$, kurang sebanyak 9 responden (75.0\%). Pemanfaatan KMS mengenai pengetahuan kader meliputi pengisian identitas, pengisian hasil penimbangan, pengisian grafik pertumbuhan, pencatatan pemberian imunisasi, pemberian vitamin $A$, dan pemberian ASI eksklusif adalah baik sebanyak 0 reponden $(0 \%)$, cukup sebanyak 3 responden (25\%), kurang sebanyak 9 responden (75\%).

Pemanfaatan KMS mengenai penggunaan KMS yaitu sebagai alat edukasi, sebagai alat bantu untuk memantau pertumbuhan anak, menilai hasil penimbangan dan memberikan pujian kepada ibu bila BB anak naik adalah baik sebanyak 0 reponden $(0 \%)$, cukup sebanyak 4 responden (33.3\%), kurang sebanyak 8 responden (66.7\%). Pemanfaatan KMS mengenai tindak lanjut penilaian KMS oleh kader meliputi tindak lanjut bila berat badan naik $(\mathrm{N})$, bila berat badan tidak naik 1 kali, dan berat badan naik 2 kali atau bila ada kelainan pertumbuhan (BGM) adalah responden dengan kategori baik adalah 0 responden (0\%), cukup 3 responden (25\%), dan kurang 9 responden $(75 \%)$

\section{KEPUSTAKAAN}

1. Infodatin. Situasi dan Analisis Gizi.Pusat Data dan Informasi. 2014

2. Depkes RI. Buku Saku Kader Posyandu. Depkes RI. Jakarta. 2009

3. Kemenkes RI. Pedoman Kader Posyandu Menuju Keluarga Sadar Gizi. Direktorat Bina Gizi. Jakarta. 2011

4. SKRT. Kader dan Posyandu di Indonesia. Jakarta. 2005

5. Riwidikdo. Metode Penelitian Kuantitatif Kualitatif dan R\&D. Bandung. Alfabeta. 2011

6. Lenocoly. Pemanfaatan KMS oleh Petugas Kesehatan. Rineka Cipta. Jakarta. 2008

7. Sugiyono. Metode Penelitian Bisnis. Bandung. Alfabeta. 2007: 10-6 
8. Permenkes RI. (2010). PMK No. 155

Tentang Penggunaan Kartu Menuju

Sehat (KMS) Bagi Balita. Jakarta. 2010

9. Sulistyorini dkk. Kartu Menuju Sehat.

Transinfo Medika. Jakarta. 2010 